Article

\title{
Controlling Segregation Behavior of Primary Si in Hypereutectic Al-Si Alloy by Electromagnetic Stirring
}

\author{
Qingchuan Zou ${ }^{1,2, *}$, Hao Tian ${ }^{1}$, Zixu Zhang ${ }^{1}$, Chengzhuo Sun ${ }^{1}$, Jinchuan Jie ${ }^{2}$, Ning Han ${ }^{3}$ (D) \\ and Xizhong An ${ }^{1, *}$ \\ 1 Key Laboratory for Ecological Metallurgy of Multimetallic Mineral of Ministry of Education, School of \\ Metallurgy, Northeastern University, Shenyang 110819, China; 20172363@stu.neu.edu.cn (H.T.); \\ 1971480@stu.neu.edu.cn (Z.Z.); 20182349@mail.neu.edu.cn (C.S.) \\ 2 School of Material Science and Engineering, Dalian University of Technology, Dalian 116024, China; \\ jiejc@neu.edu.cn \\ 3 Department of Materials Engineering, KU Leuven, 3001 Leuven, Belgium; ninghan51@126.com \\ * Correspondence: zouqingchuan@mail.neu.edu.cn (Q.Z.); anxz@mail.neu.edu.cn (X.A.)
}

Received: 4 August 2020; Accepted: 20 August 2020; Published: 21 August 2020

check for updates

\begin{abstract}
Controlling the segregation behavior of primary $\mathrm{Si}$ in the solidification process of hypereutectic Al-Si alloy is crucial for enhancing the design ability of the solidification structure. To explore the separation condition and morphological evolution of primary $\mathrm{Si}$ in detail, a series of experiments concerning the coupling effect of a temperature field and electromagnetic stirring on the segregation behavior of primary $\mathrm{Si}$ were carried out. Experimental results show that the temperature field and fluid flow in the melt are two key points for controlling the segregation behavior of primary $\mathrm{Si}$. The establishment of a temperature gradient in the Al-Si melt is a precondition for realizing the separation of primary $\mathrm{Si}$. On the basis of the temperature gradient, the electromagnetic stirring can further strengthen the separation effect for primary $\mathrm{Si}$, forming a Si-rich layer with $65 \sim 70 \mathrm{wt} . \% \mathrm{Si}$ content. The formation of the Si-rich layer is a continuous growth process of primary Si by absorbing $\mathrm{Si}$ atoms from Al-Si melt with the help of electromagnetic stirring. The separation technology for primary $\mathrm{Si}$ is proposed to realize the segregation control of primary $\mathrm{Si}$, which not only broadens the application of Al-Si alloys in the functionally gradient composites but also provides a low-cost supply strategy of Si raw materials for the solar photovoltaic industry.
\end{abstract}

Keywords: electromagnetic stirring; segregation behavior; solidification; hypereutectic Al-Si alloy; microstructure

\section{Introduction}

Hypereutectic Al-Si alloys are recognized as excellent candidates for structural application in the aircraft, automotive and electronic packaging industries, due to their excellent wear resistance, high heat resistance and low thermal expansion coefficient [1-3]. The uneven growth of the primary $\mathrm{Si}$ easily occurs in the casting solidification process of Al-Si alloy with increasing Si content, resulting in severe macro-segregation in large ingots. The macro-properties of the materials usually depend on the micro-structures, namely, the mechanical properties show a transition from uniformity to non-uniformity with a gradient segregation of second phase particles [4]. Therefore, improving macro-segregation of primary $\mathrm{Si}$ is commercially important, which plays a critical role in designing service material performance.

Numerous efforts have been made to strengthen the segregation behavior of primary Si during the solidification of Al-Si alloy by applying physical fields, such as ultrasonic field [5], super gravity field [6], electric field [7-9], static magnetic field [10], and electromagnetic stirring [11-20]. Among various 
fields, electromagnetic stirring is the most efficient method used to realize the remote transmission of solute atoms [21,22] and even to control the directional growth of dendrite [23]. As early as 1991, Ren et al. [24] identified the phenomenon of a "separated eutectic" in the unidirectional solidification process of the eutectic Al-Si alloy under a rotating magnetic field (RMF). The research of Yoshikawa et al., [11-13] indicates that the bulk flow forced by an intermediate frequency magnetic field can directionally drive primary Si particles, resulting in the axial macro-segregation of primary Si during the directional solidification of hypereutectic Al-Si alloy. Ban et al. $[25,26]$ tried to separate primary Si by using RMF at slow cooling condition and discussed the influence of the frequency of the RMF on the separation efficiency of primary Si. On the other hand, we also struggled with the fact that the electromagnetic separation of primary Si during the solidification of Al-30Si alloy has been entrenched by changing the Si content [27] and adding Sn element [28]. The morphological evolution of primary $\mathrm{Si}$ in the electromagnetic directional solidification of Al-30Si alloy was studied by Xue et al. [29] and Jiang et al. [30]. More specifically, they established a predominance area diagram for Si morphology based on the constitutional super-cooling theory, and indicated that the morphology can be controlled by adjusting the crystal growth rate, temperature gradient, and solute concentration. With over a century of research into macro-segregation, the separation of primary $\mathrm{Si}$ has been well-realized by electromagnetic stirring. However, there are many disputes about the understanding of the separation mechanism, especially regarding the issue for the separation condition and morphological evolution of primary $\mathrm{Si}$, which greatly limits the implementation of electromagnetic separation technology to large commercial ingot production.

Hence, the present work aims to confirm the separation condition and morphological evolution of primary Si during the solidification of hypereutectic Al-Si alloy under electromagnetic stirring. The separation condition for primary $\mathrm{Si}$ was determined under the coupling action of a temperature field and RMF. Moreover, the evolution process for the Si-rich layer was revealed in the electromagnetic separation process of primary Si. On the basis of fundamental understanding of the electromagnetic separation mechanism, the electromagnetic separation technology for primary Si was further developed, and its potential perspective in future industry was proposed.

\section{Experimental Procedure}

\subsection{The Separation Condition of Primary Si}

The hypereutectic Al-30 wt.\% Si alloy (in weight) was prepared by melting the metallurgical-grade $\mathrm{Si}$ (MG-Si, purity $99.7 \mathrm{wt} . \%$ ) and commercial $\mathrm{Al}$ (purity $99.7 \mathrm{wt} . \%$ ) in the medium frequency induction furnace (power $25 \mathrm{kw}$ ) with an argon atmosphere. To determine the separation condition for primary $\mathrm{Si}$, two groups of experiments were carried out. The first group was conducted with a changed cooling condition by adjusting the position of the insulation materials on the outside surface of a graphite crucible to investigate the effect of the temperature field on the segregation behavior of primary Si. The pre-prepared Al-30Si melt was moved to a SiC electric furnace and held at $830{ }^{\circ} \mathrm{C}$ for $20 \mathrm{~min}$ to enable uniform melting. Then, the Al-30Si melt was poured into a graphite crucible $\left(\Phi 60 \mathrm{~mm}\right.$, preheated at $\left.830^{\circ} \mathrm{C}\right)$. The insulation materials were coated on the different positions of the graphite crucible to establish the required temperature field into the Al-30Si melt (Figure 1a). K-type thermocouples, connected to a multichannel data logging system, were inserted into the center of the melt to record the cooling curves. The second group was conducted with forced melt flow by introducing an RMF based on the above cooling condition, which mainly aims to reveal the role of electromagnetic stirring on the separation of primary Si. The Al-30Si melt was poured into a graphite crucible with the above cooling condition. The graphite crucible was placed into the RMF with a frequency of $50 \mathrm{~Hz}$ and a magnetic flux density of $25 \mathrm{mT}$ which was induced by a three-phase-three-pole magnetic generator (Figure 1b). The magnetic field was switched on when the melt was cooled to $810^{\circ} \mathrm{C}$. The concept and logical relationship for each experimental group are given in Table 1. 
(a)

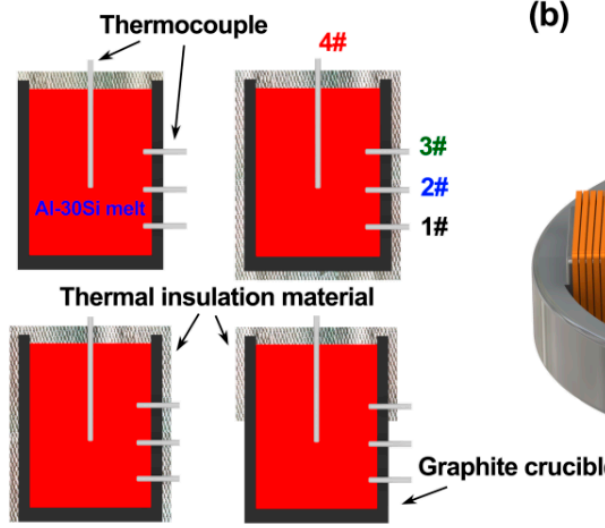

(b)

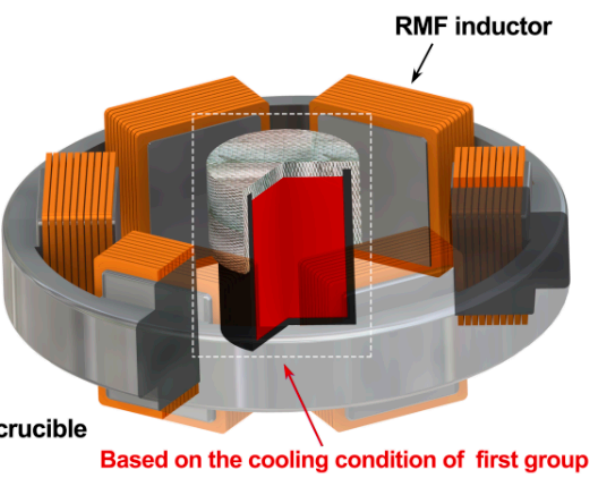

Figure 1. Schematic diagram of the experimental device for each group: (a) insulation details of the graphite crucible, (b) structural features of the rotating magnetic field (RMF).

Table 1. The design details and the logical relationship of each group.

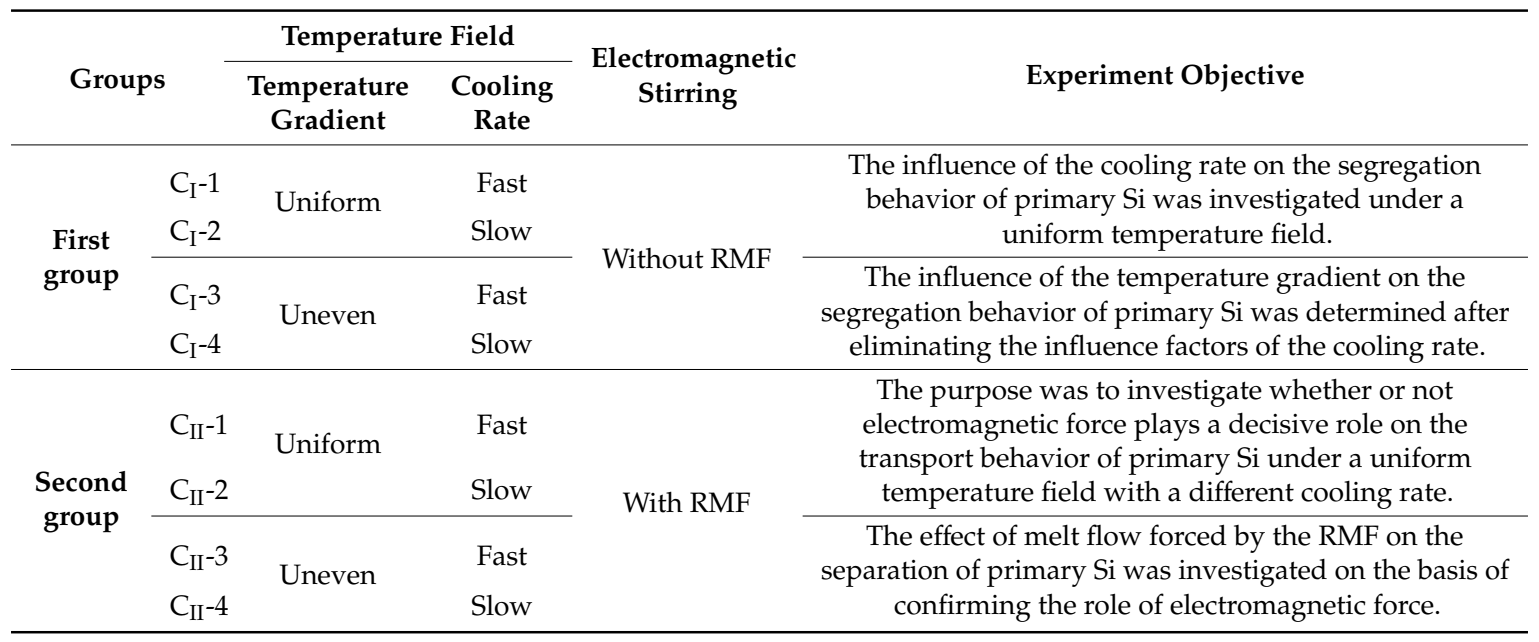

\subsection{The Separation Process of Primary Si}

In order to clarify the formation process for the Si-rich layer, a series of experiments were designed, and the corresponding schematic flow is given in Figure 2. The Al-30Si alloy was melted to $830^{\circ} \mathrm{C}$ in the $\mathrm{SiC}$ electric furnace and then cooled slowly to specific temperatures $\left(790,760,730\right.$ and $700{ }^{\circ} \mathrm{C}$ ) by turning off the power (Figure 2a). With decrease of temperature, the Si crystals initially precipitated from the melt to form the primary Si particles. Correspondingly, the number of $\mathrm{Si}$ atoms in the melt was gradually reduced. According to the Al-Si alloy phase diagram [31], the precipitated mass fractions of the primary $\mathrm{Si}$ were $0,45,25$ and $5 \%$ at temperatures of 790, 760, 730 and $700{ }^{\circ} \mathrm{C}$, respectively. In this cooling process with the furnace, the Al-30Si melt was stirred by a ceramic stick to prevent the primary Si phase from forming a mesh-shape around the inner wall of crucible. It is noteworthy that the Al-30Si melt was contained by the graphite crucible with an optimum separation condition. When the predetermined temperature was reached, the semisolid Al-30Si melt was transferred to the RMF inductor for the electromagnetic separation of primary Si (Figure 2b). The solidified ingots were cut along the axis of the cylinder to exhibit the distribution characteristics of primary $\mathrm{Si}$, and the microstructures were characterized by an optical microscope. All the experiments were conducted at least three times in order to assess reproducibility. 
(a)

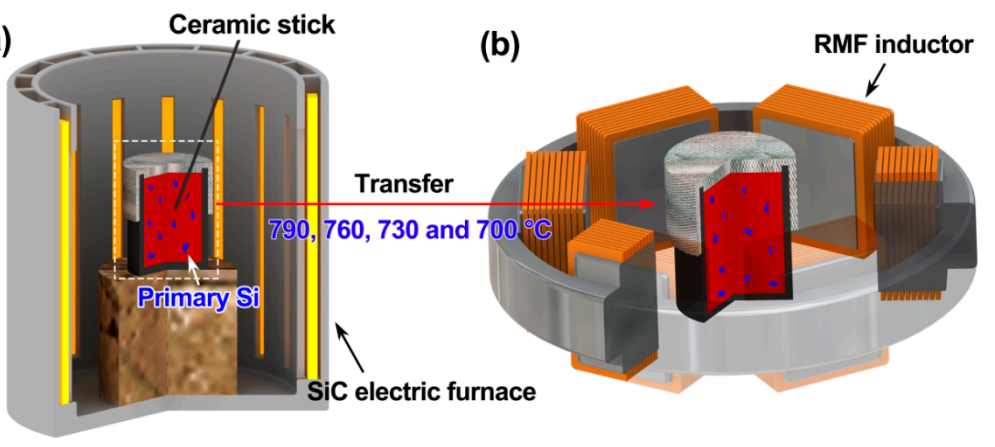

Figure 2. Experiment flow chart of the formation process of the Si-rich layer: (a) Cooling with furnace, (b) RMF inductor.

\section{Results and Discussion}

\subsection{Electromagnetic Separation Condition of Primary Si}

\subsubsection{Effect of Temperature Field on the Segregation Behavior of Primary Si}

The cooling curves of the Al-30Si melt with different insulation conditions were recorded by the multichannel data logging system (see Figure 3 ). Without the insulation layer $\left(C_{I}-1\right)$, the temperature field inside the Al-30Si melt tended to be uniformly distributed, and the cooling rate was approximately $60^{\circ} \mathrm{C} / \mathrm{min}$ (Figure 3a). Under the condition of complete insulation $\left(\mathrm{C}_{\mathrm{I}}-2\right)$, the cooling rate of the Al-30Si melt was reduced to $1.5^{\circ} \mathrm{C} / \mathrm{min}$, and the distribution of the temperature field was more uniform in the entire melt (Figure $3 b$ ). When the insulation materials were coated on the top and periphery of the crucible $\left(\mathrm{C}_{\mathrm{I}}-3\right)$, the heat preferentially escaped through the bottom of the Al-30Si melt during slow cooling, forming a temperature gradient $\left(0.5^{\circ} \mathrm{C} / \mathrm{mm}\right)$ in the axial plane (Figure $\left.3 \mathrm{c}\right)$. With the heat dissipation area further expanded $\left(\mathrm{C}_{\mathrm{I}}-4\right)$, the temperature gradient in the entire Al-30Si melt became more obvious, as shown in Figure 3d. There were two kinds of orientation: one was a top-bottom temperature gradient $\left(1.5^{\circ} \mathrm{C} / \mathrm{mm}\right)$ in the axial direction, while the other was an inside-out temperature gradient $\left(0.3^{\circ} \mathrm{C} / \mathrm{mm}\right)$ in the radial direction.
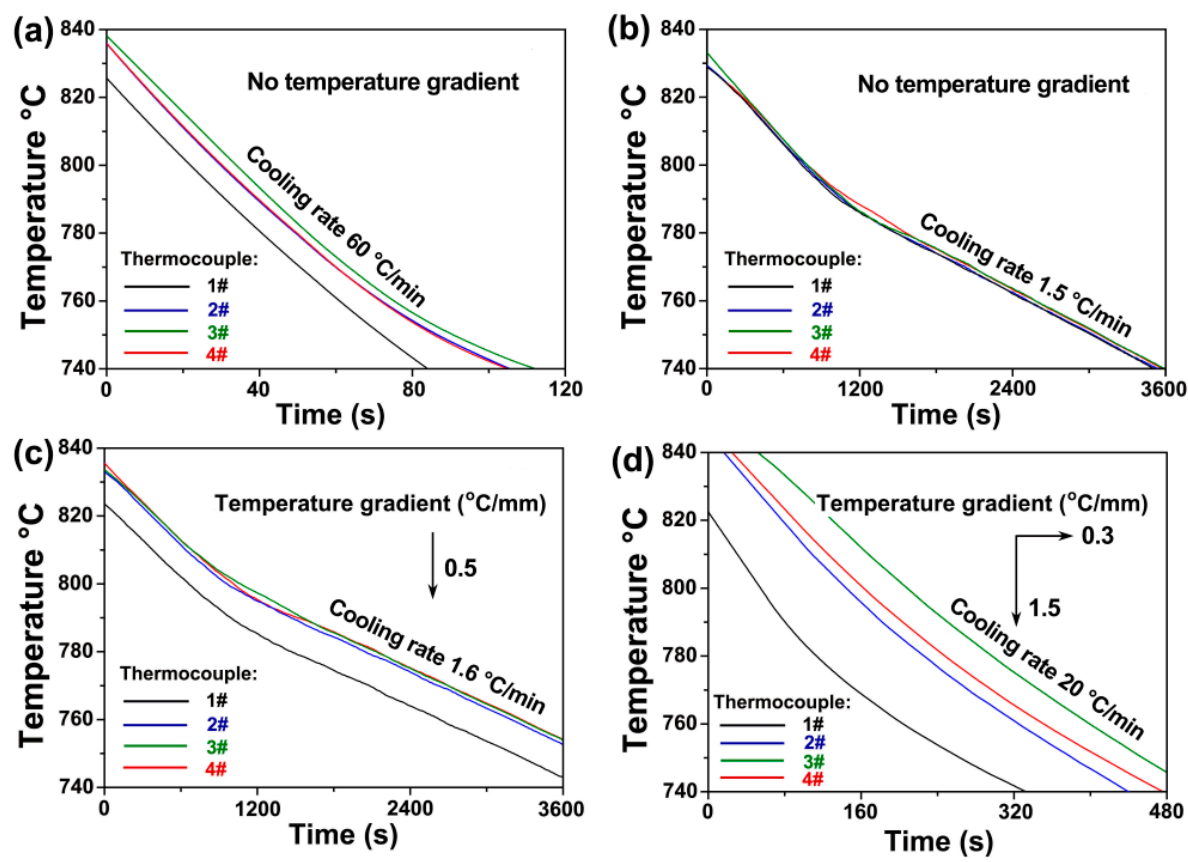

Figure 3. Cooling curves of the Al-30Si alloy with different insulation conditions: (a) $C_{I}-1$, (b) $C_{I}-2$, (c) $\mathrm{C}_{\mathrm{I}}-3$, (d) $\mathrm{C}_{\mathrm{I}}-4$. 
To more directly reflect the effect of the temperature field on the segregation behavior of primary $\mathrm{Si}$, the vertical-sections of Al-30Si alloy solidified with different cooling conditions were observed (see Figure 4). For the case without an insulation layer, the primary Si tended to be uniformly distributed in the entire ingot (Figure 4a). The heat loss in the Al-30Si melt became more uniform and slower because of the complete insulation, thus promoting a uniform distribution and growth of primary $\mathrm{Si}$ (Figure $4 \mathrm{~b}$ ). By comparing Figure 4a to Figure $4 \mathrm{~b}$, it was not difficult to find that the segregation behavior of primary Si was not controlled by changing the cooling rate under the condition of a uniform temperature field. This is attributed to the uniform nucleation of primary $\mathrm{Si}$ in the solidification process of Al-30Si alloy without temperature gradient. For an uneven temperature field, the distribution of primary Si changed significantly in the vertical-section of the ingot. The primary Si was segregated toward the bottom of the Al-30Si melt under the effect of the temperature gradient (Figure 4c,d). Therefore, it could be concluded that the establishment of the temperature gradient in the Al-30Si melt was a precondition for realizing the separation of primary Si.
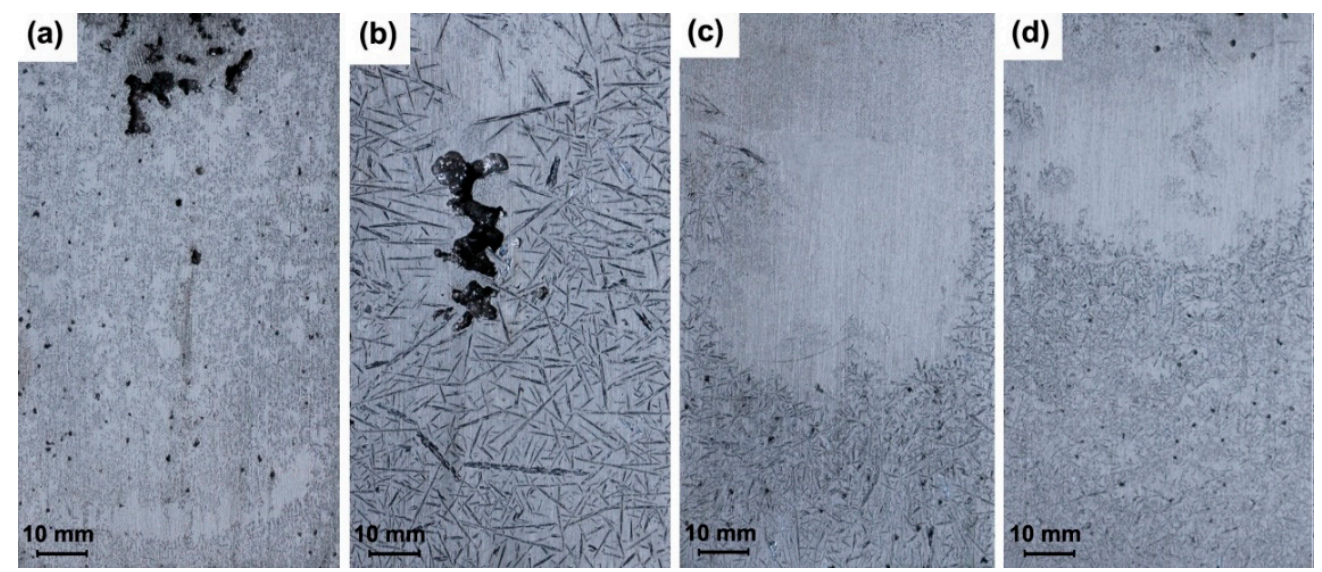

Figure 4. Vertical-sections of Al-30Si alloys with different cooling conditions: (a) $C_{I}-1,(b) C_{I}-2$, (c) $C_{I}-3$, (d) $\mathrm{C}_{\mathrm{I}}-4$.

\subsubsection{Role of Electromagnetic Stirring in the Separation Process of Primary Si}

On the basis of the above insulating condition, an RMF was further introduced to clarify the influence of coupling between the temperature field and the electromagnetic field on the segregation behavior of primary Si. Figure 5 shows the vertical-sections of Al-30Si alloy solidified under the coupling effect of a temperature field and electromagnetic field. Based on Figure $5 a, b$, during electromagnetic solidification without a temperature gradient for both rapid and slow cooling $\left(\mathrm{C}_{\mathrm{II}}-1\right.$ and $\left.\mathrm{C}_{\mathrm{II}}-2\right)$, the primary $\mathrm{Si}$ was evenly distributed in the entire Al-30Si alloy. This finding indicated that electromagnetic stirring was not a decisive role for the separation of primary $\mathrm{Si}$. However, under the condition of a temperature gradient $\left(\mathrm{C}_{\mathrm{II}}-3\right.$ and $\left.\mathrm{C}_{\mathrm{II}}-4\right)$, the primary $\mathrm{Si}$ was separated by the electromagnetic stirring. The primary $\mathrm{Si}$ was transferred from the high temperature region to the low temperature region under the coupling action of the temperature gradient and the RMF, eventually forming a Si-rich layer (Figure $5 c$,d). In addition, the RMF could fully separate the primary Si under axial and radial temperature gradients (Figure 5d). From Figure 4c,d, it was not difficult to obtain the conclusion that the separation of primary Si could be further strengthened by electromagnetic stirring on the base of the temperature gradient. 

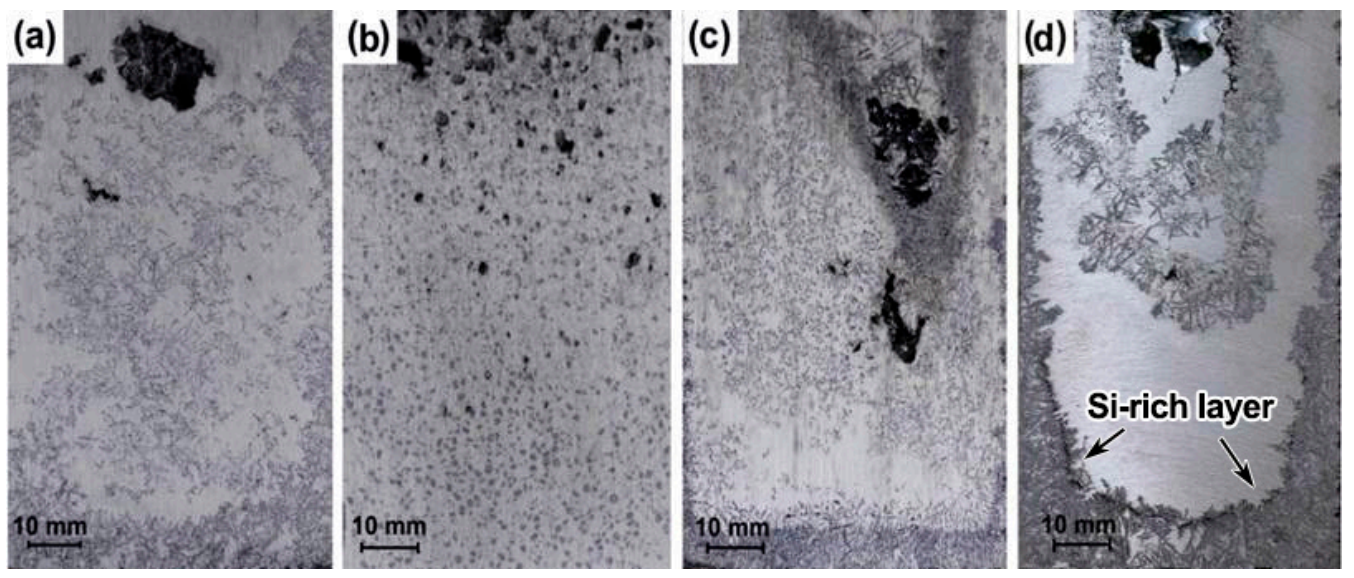

Figure 5. Vertical-sections of Al-30Si alloys solidified under coupling action of a temperature field and an electromagnetic field: (a) $\mathrm{C}_{\mathrm{II}}-1$, (b) $\mathrm{C}_{\mathrm{II}}-2$, (c) $\mathrm{C}_{\mathrm{II}}-3$, (d) $\mathrm{C}_{\mathrm{II}}-4$.

\subsection{Electromagnetic Separation Process of Primary Si}

\subsubsection{The Transport Behavior of Primary Si under Electromagnetic Stirring}

The vertical-sections of the solidified Al-30Si alloy were observed by starting the RMF at temperatures of 790, 760, 730 and $700{ }^{\circ} \mathrm{C}$ (see Figure 6). Note that the primary Si particles marked by arrow 1 were precipitated from the Al-30Si melt in furnace cooling before being placed under the RMF; the Si-rich layer marked by arrow 2 was formed after starting the RMF. The primary Si particles pre-precipitated by slow cooling in the furnace to $700{ }^{\circ} \mathrm{C}$ remained evenly distributed in the entire ingot under the RMF (see Figure 6a and illustration of Figure 6a). This finding also indicates that the electromagnetic force could not separate the primary Si phase in the form of particles from the Al-Si melt. With the rise of the cooling temperature in the furnace, the number of pre-precipitated primary $\mathrm{Si}$ particles decreased while the Si-rich layer gradually formed (Figure $6 \mathrm{~b}, \mathrm{c}$ ). When the temperature reached $790{ }^{\circ} \mathrm{C}$ (liquidus temperature), the primary Si particles disappeared completely, and a layer structure with a Si-rich outer layer/Si-poor inside region is formed (Figure 6d). The Si-rich layer as the cooling temperature increased in the furnace is attributed to the fact that the content of Si atoms in the residual melt increased as the number of pre-precipitated primary Si particles decreased. Therefore, the electromagnetic separation process of primary $\mathrm{Si}$ is not transport in the form of primary Si particles to the periphery of the ingot by an electromagnetic force but continual growth by absorbing $\mathrm{Si}$ atoms from the melt under the action of electromagnetic stirring.
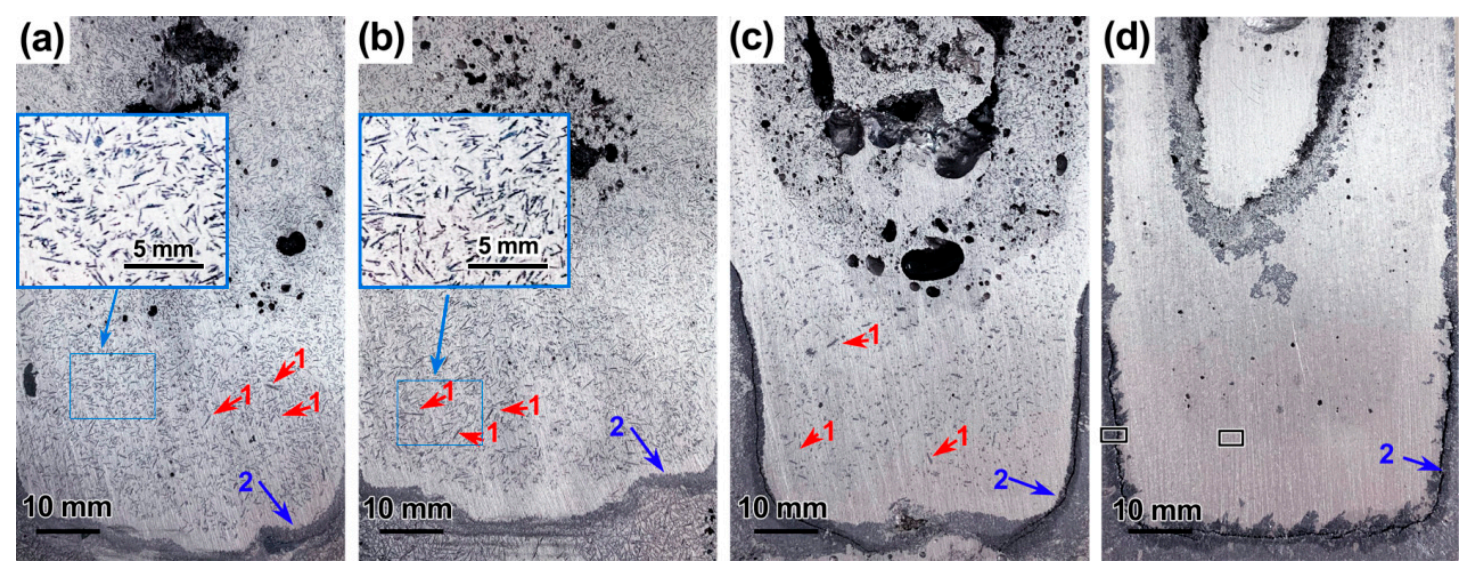

Figure 6. Vertical-sections of Al-30Si alloys solidified by starting RMF at temperatures of (a) $700{ }^{\circ} \mathrm{C}$, (b) $730{ }^{\circ} \mathrm{C}$, (c) $760{ }^{\circ} \mathrm{C}$, (d) $790{ }^{\circ} \mathrm{C}$. 
To reveal the electromagnetic separation process for primary Si, the microstructures of the Si-rich layer and the Si-poor region of the Al-30Si alloy with the best separation condition were observed (marked in Figure 6d), and the results are shown in Figure 7. According to the morphological characteristics of primary Si (Figure 7a), the formation process for the Si-rich layer can be divided into three stages: segregation growth, continuous growth and merger growth. First, driven by the temperature gradient, the primary Si particles grew in parallel in close proximity to each other based on the inner wall surface of the graphite crucible (Figure $7 \mathrm{a}(\mathrm{I})$ ). Then, the primary Si phases grew continuously and intertwined into a network-like structure by absorbing Si atoms from the melt. The eutectic Al-Si structure was distributed in the inter-network region of primary Si (Figure 7a(II)). As the electromagnetic stirring progressed, the primary Si phases interconnected with each other more obviously, and the volume fraction of the eutectic Al-Si structure in this area was dramatically decreased (Figure 7a(III)). Apparently, the centrifugal extrusion generated by the RMF was important for increasing the mass fraction of primary $\mathrm{Si}$ in the Si-rich layer, which was measured in the range of 65 70 wt.\% when the magnetic intensity was maintained at $25 \mathrm{mT}$. Figure $7 \mathrm{~b}$ reveals that the Si-poor region of the ingot was mainly composed of the eutectic Al-Si structure, and no primary Si could be found in this area. This finding indicated that the electromagnetic separation limit for primary Si was reached when the content of Si atoms in the Al-Si melt was reduced to the eutectic composition.
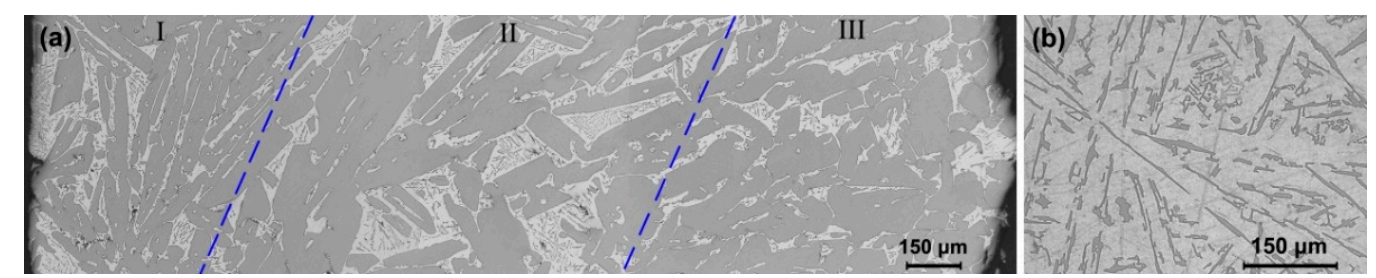

Figure 7. Microstructures of (a) the Si-rich layer and (b) the Si-poor region of the Al-30Si alloy under the best separation condition.

\subsubsection{Electromagnetic Separation Mechanism of Primary Si}

According to the above analysis, the electromagnetic separation of primary Si involves a complex coupling growth process based on the temperature field, flow field, and solute distribution. Figure 8 shows a schematic diagram of the electromagnetic segregation process for primary Si under the coupling effect of a temperature gradient and electromagnetic stirring. When the RMF is turned on, the liquid metal is driven by virtue of the azimuthal Lorentz force induced, which leads to the formation of a swirling flow in the azimuthal direction. Then a secondary flow in the meridional plane appears, resulting from the imbalance between centrifugal force and radial pressure gradient (Figure 8a). Although the secondary flow condition is relatively weak, comprising only approximately $30 \%$ of the primary flow condition [32], it plays an important role in improving the transport of the solute atoms in the axial direction of the Al-Si melt. With cooling proceeding, the heat preferentially escapes through the bottom of the crucible, and thereby, the temperature gradient in the Al-30Si melt is formed. The establishment of this temperature gradient provides a priority nucleation zone for separating primary Si. The Si crystals are pre-nucleated near the bottom of the melt because the temperature there is lower (Figure $8 b$ ). Then, the secondary flow promotes continuously the growth of the pre-nucleated Si crystals by absorbing Si atoms from the bulk Al-Si melt, finally resulting in the macro-segregation of primary Si (Figure 8c). When the content of Si atoms in the melt is reduced to the eutectic composition, the separation process reaches the limitation to form a Si-rich layer (Figure 8d). As the solidification progresses, the additional pressure on the inner wall caused by the swirling flow compresses the Si-rich layer and further crowds out the Al-rich melt from the inter-network region of primary Si, thus increasing the density of the primary Si within the Si-rich layer. 

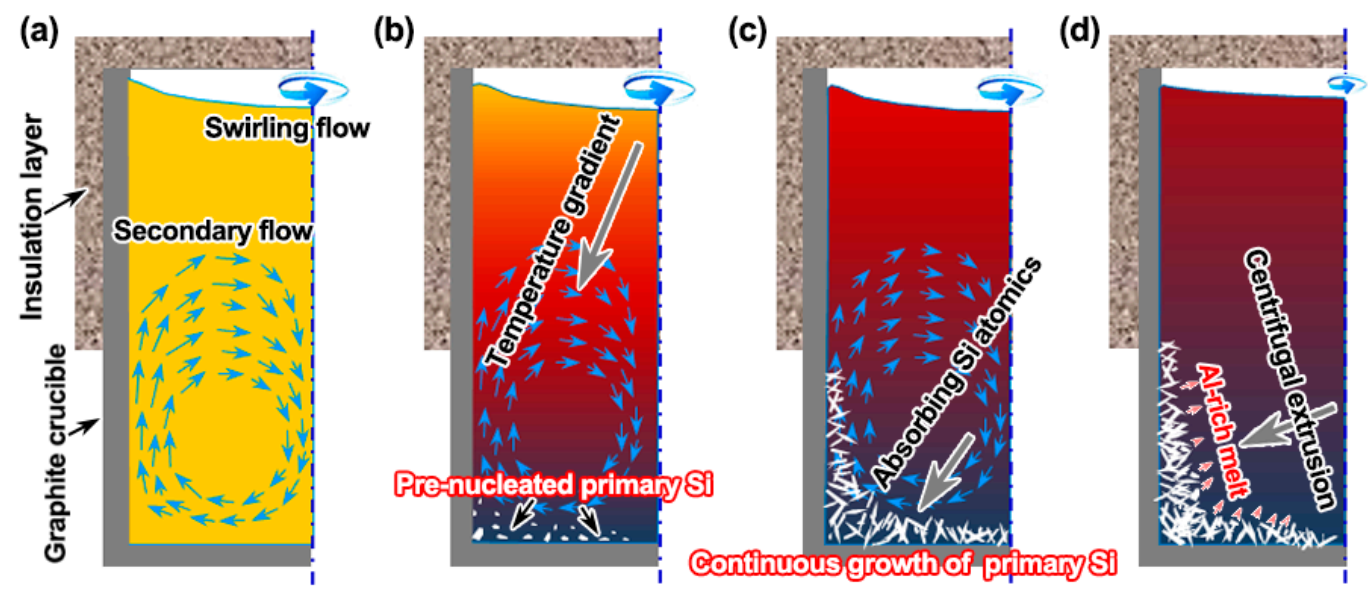

Figure 8. Schematic diagram of the electromagnetic segregation process of primary Si: (a) characteristics of flow pattern, (b) nucleation stage of Si crystals, (c) continuous growth stage of primary $\mathrm{Si}$, (d) merger formation stage of Si-rich layer.

\subsection{Application Exploration of Electromagnetic Separation of Primary Si}

\subsubsection{The Preparation of In-Situ Particle Reinforced Al-Base Gradient Composites}

From the perspective of the structural design of composite materials [33], if the primary Si that serves as a hard phase can be directionally separated to form a gradient structure with a Si-rich/Si-poor layer, different sides of the materials can present different functions. On the basis of a full understanding of the electromagnetic separation mechanism, the hypereutectic Al-18Si in-situ graded gear reinforced with primary Si particles was fabricated successfully by controlling the coupling between the temperature field and the electromagnetic field (Figure 9a). An analysis of the microstructures revealed that the Si-rich outer layer was formed with a high mass fraction of primary $\mathrm{Si}$; the Si-poor inside region was mainly composed of the Al-Si eutectic structure (Figure 9b). The properties of the Si-rich layer and Si-poor region were characterized (as marked by the positions 1 6 in Figure 9a), and the results are shown in Figure 9c. It was clear that the distribution of the hardness presented a step-like feature between the Si-rich outer layer and the Si-poor inside region. The hardness of the Si-rich layer was approximately $200 \mathrm{Hv}$ higher than that of the Si-poor region. The primary Si-rich outer layer, which has a higher hardness, as the tooth of the gear, can effectively enhance the wear resistance. Meanwhile, the eutectic Si-poor inside region can improve the impact resistance of the gear due to its good toughness. It is expected that this hypereutectic Al-Si composite material with a Si-rich layer/Si-poor region can be considered as a kind of designable graded gear, which has great potential for practical application in astronautics and aeronautics.
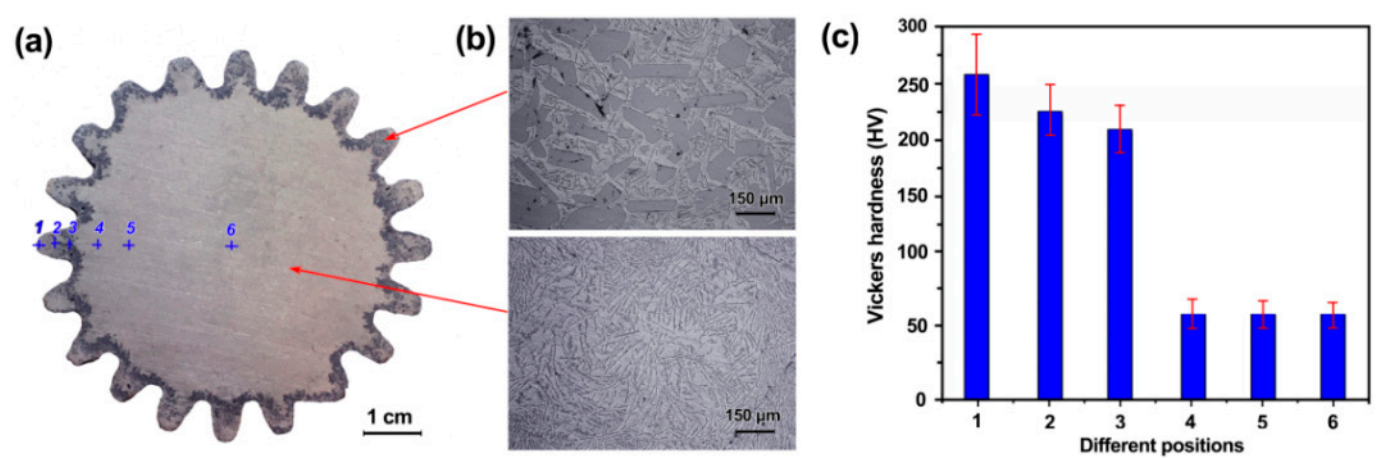

Figure 9. (a) Cross-section images of hypereutectic Al-18Si in-situ graded gear, (b) microstructures of the Si-poor region and the Si-rich layer, (c) Vickers hardness values for different positions. 


\subsubsection{The Purification of Metallurgical Grade $\mathrm{Si}$}

For upgrading MG-Si to solar-grade $\mathrm{Si}$ (SOG-Si), the solidification purification with the hypereutectic Al-Si alloy as a novel metallurgical process shows potential in the manufacture of low-cost and environmentally friendly silicon solar cells. In the solidification process of hypereutectic Al-Si alloys, the purification of Si crystals can be achieved by redistributing the impurity elements at the interfacial front of the primary $\mathrm{Si} / \mathrm{Al}-\mathrm{Si}$ melt. However, the primary $\mathrm{Si}$ is uniformly distributed in the entire ingot because the primary $\mathrm{Si}$ and the Al-Si melt have a similar density, which leads to the result that it is hard to collect the high-purity Si. Therefore, separating primary $\mathrm{Si}$ is the bottleneck restricting industrial applications.

To solve the above problem, we have developed an electromagnetic continuous separation technology of primary Si to realize the efficient collection of the high-purity Si [34]. The continuous growth of Si crystals was controlled by the RMF during semi-continuous casting of the hypereutectic Al-30Si alloy to achieve the efficient separation of primary Si (Figure 10a). The Si-rich layer was peeled from the periphery of the ingot, followed by acid leaching to collect the primary Si (Figure 10b). By applying the mass production advantage of the continuous separation technique, the primary $\mathrm{Si}$ was purified via multiple solidification purifying steps. The results of the sample for the purity test showed that the content of all impurity elements, except for $\mathrm{Al}$, in the primary $\mathrm{Si}$ could be reduced to a solar-grade level by refining just three times (Figure 10c). A poly-crystalline Si ingot was prepared by smelting the primary Si crystals, which satisfied the purity requirement (Figure 10d). Table 2 gives the summary of the impurity removal effect by the traditional metallurgical method and continuous separation technique of primary Si. It can be clearly detected that the traditional metallurgical method needs to run through the coupling of three refining processes at five-step high temperatures (over $1500^{\circ} \mathrm{C}$ ) to gradually remove the metallic impurities, B, and P in the raw material MG-Si. Compared to the traditional metallurgical method, the continuous separation technique for primary Si was obviously superior in terms of cost and convenience, as it only needs to meet the requirements of SOG-Si by three times solidification at low temperatures (under $950{ }^{\circ} \mathrm{C}$ ). Therefore, the continuous separation technique for primary $\mathrm{Si}$ is a possible energy-saving way to provide low-cost SOG-Si for the solar photovoltaic industry.

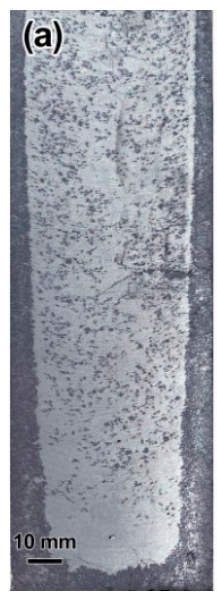

(b)

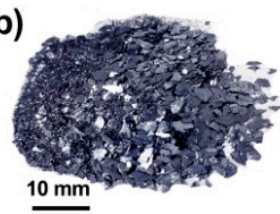

(d)

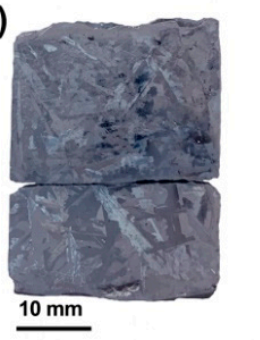

(c)

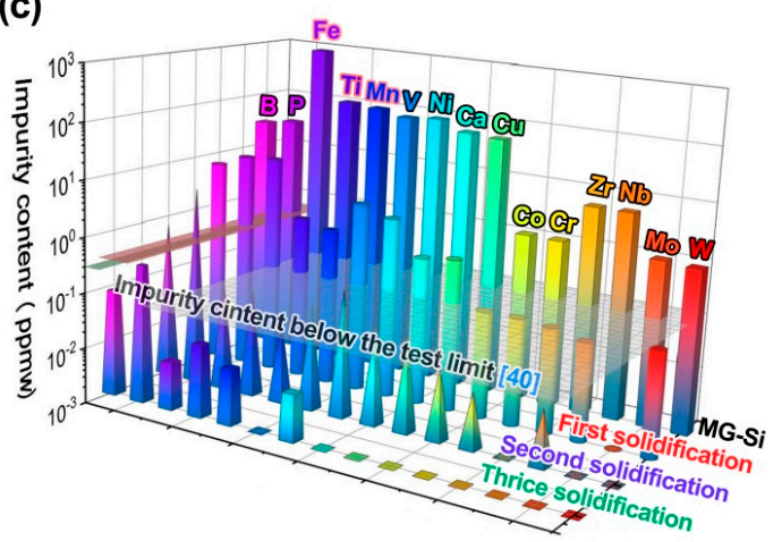

Figure 10. (a) Vertical section of Al-30Si alloy prepared by the continuous separation technique, (b) image of the collected primary Si particles, (c) impurity contents in the primary Si after each solidification purifying, (d) poly-crystalline Si ingot. 
Table 2. The summary of the impurity removal effect by the traditional metallurgical method and continuous separation technique of primary Si.

\begin{tabular}{|c|c|c|c|c|c|c|c|}
\hline & \multirow{2}{*}{$\begin{array}{l}\text { Purification } \\
\text { Method }\end{array}$} & \multirow[t]{2}{*}{ Purification Process } & \multirow{2}{*}{$\begin{array}{l}\text { Objective/ppmw } \\
\text { [35] }\end{array}$} & \multicolumn{3}{|c|}{$\begin{array}{l}\text { Impurity Contents in Si after Each } \\
\text { Refining/ppmw }\end{array}$} & \multirow[t]{2}{*}{ Rf. } \\
\hline & & & & Once & Twice & Thrice & \\
\hline \multirow{7}{*}{$\begin{array}{l}\text { Traditional } \\
\text { metallurgical } \\
\text { process }\end{array}$} & \multirow{3}{*}{$\begin{array}{l}\text { First step: } \\
\text { Slag refining to } \\
\text { remove B }\end{array}$} & $\mathrm{Na}_{2} \mathrm{O}-\mathrm{SiO}_{2}$, temperature: $170{ }^{\circ} \mathrm{C}, 30 \mathrm{~min}$ & \multirow{3}{*}{$<0.3$} & $24 \rightarrow 0.8$ & $0.8 \rightarrow 0.4$ & $0.4 \rightarrow 0.1$ & [36] \\
\hline & & $\begin{array}{l}\mathrm{CaO}-\mathrm{SiO}_{2}-\mathrm{LiF} \text {, temperature: } 1550^{\circ} \mathrm{C}, 240 \mathrm{~min} \\
\mathrm{CaO}-\mathrm{SiO}_{2}-\mathrm{Li}_{2} \mathrm{O} \text {, temperature: } 1550^{\circ} \mathrm{C}, 240 \mathrm{~min}\end{array}$ & & $\begin{aligned} 22 & \rightarrow 3.3 \\
24 & \rightarrow 3.6\end{aligned}$ & & & [37] \\
\hline & & $\mathrm{CaF}_{2}-\mathrm{Al}_{2} \mathrm{O}_{3}-\mathrm{CaO}-\mathrm{SiO}_{2}$, temperature: $1800{ }^{\circ} \mathrm{C}, 240 \mathrm{~min}$ & & $25 \rightarrow 5.1$ & $5.1 \rightarrow 2.6$ & & [38] \\
\hline & \multirow{2}{*}{$\begin{array}{l}\text { Second step: } \\
\text { Vacuum plasma } \\
\text { refining to remove } \mathrm{P}\end{array}$} & Power: $200 \mathrm{~kW}$ & \multirow[b]{2}{*}{$<0.5$} & $25 \rightarrow<0.1$ & & & [39] \\
\hline & & $\begin{array}{l}\text { Vacuum degree: } 10^{-2} \sim 10^{-3} \mathrm{~Pa} \text {, Power: } 21 \mathrm{~kW}, 30 \mathrm{~min} \\
\text { Vacuum degree: } 5 \times 10^{-2} \mathrm{~Pa} \text {, Power: } 30 \mathrm{~kW}, 30 \mathrm{~min}\end{array}$ & & $\begin{array}{l}15 \rightarrow<0.1 \\
33 \rightarrow<0.1\end{array}$ & & & [40] \\
\hline & \multirow{2}{*}{$\begin{array}{l}\text { Third step: } \\
\text { Directional } \\
\text { solidification to } \\
\text { remove the metallic }\end{array}$} & Temperature: $1414^{\circ} \mathrm{C}$, Solidification rate: $0.6 \mathrm{~mm} / \mathrm{min}$ & \multirow{2}{*}{$<0.1$} & $\begin{aligned} \text { Fe } 2800 \rightarrow 0.29 \\
\text { Ti } 140 \rightarrow<0.1\end{aligned}$ & & & [41] \\
\hline & & $\begin{array}{l}\text { Power: } 600 \mathrm{~kW} \text {, Solidification rate: } 0.6 \mathrm{~mm} / \mathrm{min} \\
\text { Power: } 800 \mathrm{~kW} \text {, Solidification rate: } 0.18 \mathrm{~mm} / \mathrm{min}\end{array}$ & & $\begin{array}{c}\text { Fe } 1000 \rightarrow<10 \\
\text { Ti } 200 \rightarrow<10\end{array}$ & $\begin{array}{l}\mathrm{Fe}<10 \rightarrow<0.1 \\
\mathrm{Ti}<10 \rightarrow<0.1\end{array}$ & & [39] \\
\hline In this work & $\begin{array}{l}\text { Continuous } \\
\text { separation technique } \\
\text { of primary } \mathrm{Si}\end{array}$ & $\begin{array}{l}\text { Casting temperature: } 950{ }^{\circ} \mathrm{C} \\
\text { Magnetic flux density: } 35 \mathrm{mT} \\
\text { Electromagnetic frequency: } 50 \mathrm{~Hz} \\
\text { Casting speed: } 50 \mathrm{~mm} / \mathrm{min}\end{array}$ & $\begin{array}{l}<0.3 \\
<0.5 \\
<0.1\end{array}$ & $\begin{aligned} & \text { B } 21.2 \rightarrow 4.3 \\
& \text { P } 38.5 \rightarrow 11.2 \\
& \text { Fe } 987 \rightarrow<10.6 \\
& \text { Ti } 110 \rightarrow<1.3\end{aligned}$ & $\begin{aligned} 4.3 & \rightarrow 0.8 \\
11.2 & \rightarrow 3.8 \\
10.6 & \rightarrow<0.1 \\
1.3 \rightarrow & \rightarrow 0.1\end{aligned}$ & $\begin{aligned} 0.8 & \rightarrow<0.1 \\
3.8 & \rightarrow 0.3\end{aligned}$ & \\
\hline
\end{tabular}




\section{Conclusions}

In the present work, the separation condition and morphological evolution for primary $\mathrm{Si}$ in the solidification of hypereutectic Al-Si alloy was investigated under electromagnetic stirring. The main results and conclusions can be summarized as follows:

1. The temperature field and fluid flow in the melt are two key points for controlling the segregation behavior of primary Si. The establishment of a temperature gradient in the Al-Si melt was determined to be a precondition for realizing the separation of primary Si. Electromagnetic stirring can further strengthen the separation effect of primary Si on the basis of the temperature gradient.

2. The formation of a Si-rich layer is based on the continuous growth of primary Si via the absorption of $\mathrm{Si}$ atoms from the Al-Si melt with the help of secondary flow. The Al-rich melt can be squeezed out in the Si-rich layer under the centrifugal effect of the primary flow, resulting in an increasing mass fraction of primary Si up to 65 70 wt.\% under a magnetic intensity of $25 \mathrm{mT}$.

3. Based on an understanding of the separation mechanism, the segregation control of primary Si can be achieved successfully by coupling the temperature gradient and electromagnetic stirring. The separation technology for primary Si reported in this study not only presents a new design concept for hypereutectic Al-Si in-situ graded gears for the fields of astronautics and aeronautics, but also proposes a new energy-saving strategy to provide low-cost SOG-Si for the solar photovoltaic industry.

Author Contributions: Conceptualization, Q.Z. and J.J.; methodology, Q.Z., H.T. and C.S.; software, Q.Z., H.T. and C.S.; validation, Q.Z. and N.H.; investigation, Q.Z. and Z.Z.; resources, Q.Z. and N.H.; writing-original draft preparation, Q.Z.; writing-review and editing, Q.Z., X.A. and N.H.; funding acquisition, Q.Z. All authors have read and agreed to the published version of the manuscript.

Funding: The authors wish to express their appreciation for the support of the National Training Program of Innovation and Entrepreneurship for Undergraduates (S202010145099), the Fundamental Research Funds for the Central Universities (Nos. N2024001, N2025041), the National Natural Science Foundation of China (No. 51901038), and the China Post-doctoral Science Foundation (No. 2019M661112).

Conflicts of Interest: The authors declare no conflict of interest.

\section{References}

1. Zou, M.; Zhao, D.G.; Wang, Z.Q.; Geng, H.R. Complex modification of hypereutectic Al-Si alloy by a new Al-Y-P master alloy. Met. Mater. Int. 2015, 21, 646-651.

2. Wang, R.Y.; Lu, W.H.; Hogan, L.M. Microstructure-strengthening interrelationship of an ultrasonically treated hypereutectic Al-Si (A390) alloy. Met. Mater. Int. 2018, 24, 1376-1385.

3. Mao, F.; Wei, S.Z.; Chen, C.C.; Zhang, C.; Wang, X.D.; Cao, Z.Q. Modification of the silicon phase and mechanical properties in Al-40Zn-6Si alloy with Eu addition. Mater. Des. 2020, 186, 108268. [CrossRef]

4. Jin, F.W.; Ren, Z.M.; Ren, W.L.; Deng, K.; Zhong, Y.B.; Yu, J.Y. Effects of a high-gradient magnetic field on the migratory behavior of primary crystal silicon in hypereutectic Al-Si alloy. Sci. Technol. Adv. Mater. 2008, 9, 024202. [CrossRef] [PubMed]

5. Zhang, Z.T.; Li, T.J.; Yue, H.Y.; Zhang, J.; Li, J. Study on the preparation of Al-Si functionally graded materials using power ultrasonic field. Mater. Des. 2009, 30, 851-856. [CrossRef]

6. Li, J.W.; Guo, Z.C.; Tang, H.Q.; Wang, Z.; Sun, S.T. Si purification by solidification of Al-Si melt with super gravity. Trans. Nonferr. Met. Soc. China 2012, 22, 958-963. [CrossRef]

7. Zhang, Y.H.; Miao, X.C.; Shen, Z.Y.; Han, Q.Y.; Song, C.J.; Zhai, Q.J. Macro segregation formation mechanism of the primary silicon phase in directionally solidified Al-Si hypereutectic alloys under the impact of electric currents. Acta Mater. 2015, 97, 357-366. [CrossRef]

8. Li, J.Y.; Ni, P.; Wang, L.; Tan, Y. Influence of direct electric current on solidification process of Al-Si alloy. Mater. Sci. Semicond. Process. 2017, 61,79-84. [CrossRef]

9. Zhang, Y.H.; Ye, C.Y.; Xu, Y.Y.; Zhong, H.G.; Chen, X.R.; Miao, X.C.; Song, C.J.; Zhai, Q.J. Influence of growth velocity on the separation of primary silicon in solidified Al-Si hypereutectic alloy driven by a pulsed electric current. Metals 2017, 7, 184. [CrossRef] 
10. Shen, Z.; Zhou, B.F.; Zhong, Y.B.; Zheng, T.; Ren, W.; Lei, Z.; Ren, Z. Revealing influence mechanism of a transverse static magnetic field on the refinement of primary dendrite spacing during directional solidification. J. Cryst. Growth 2019, 517, 54-58. [CrossRef]

11. Takeshi, Y.; Morita, K. Refining of silicon during its solidification from a Si-Al melt. J. Cryst. Growth 2019, 311, 776-779.

12. Takeshi, Y.; Morita, K. Continuous solidification of Si from Si-Al Melt under the induction heating. ISIJ Int. 2007, 47, 582-584.

13. Takeshi, Y.; Morita, K. Refining of Si by the solidification of Si-Al melt with electromagnetic force. ISIJ Int. 2007, 45, 967-971.

14. He, Y.F.; Ma, W.H.; Lv, G.Q.; Zhang, Y.F.; Lei, Y.; Yang, X. An efficient method to separate silicon from high-silicon aluminum alloy melts by electromagnetic directional solidification. J. Clean. Prod. 2018, 185, 389-398. [CrossRef]

15. Bai, X.L.; Ban, B.Y.; Li, J.W.; Fu, Z.Q.; Peng, Z.J.; Wang, C.B.; Chen, J. Effect of Ti addition on B removal during silicon refining in Al-30\%Si alloy directional solidification. Sep. Purif. Technol. 2017, 147, 345-351. [CrossRef]

16. Chen, K.; Chen, X.H.; Lei, Y.; Ma, W.H.; Han, J.X.; Yang, Z.H. Mechanism of enhancing B removal from Si with V addition using Al-Si as the refining solvent. Sep. Purif. Technol. 2018, 203, 168-177. [CrossRef]

17. Yu, W.Z.; Ma, W.H.; Lv, G.Q.; Ren, Y.S.; Xue, H.Y.; Dai, Y.N. Si purification by enrichment of primary Si in Al-Si melt. Trans. Nonferr. Met. Soc. China 2013, 23, 3476-3481. [CrossRef]

18. Yu, W.Z.; Ma, W.H.; Lv, G.Q.; Xue, H.Y.; Li, S.Y.; Dai, Y.N. Effect of electromagnetic stirring on the enrichment of primary silicon from Al-Si melt. J. Cryst. Growth 2014, 405, 23-28. [CrossRef]

19. Jie, J.C.; Zou, Q.C.; Wang, H.W.; Sun, J.L.; Lu, Y.P.; Wang, T.M.; Li, T.J. Separation and purification of Si from solidification of hypereutectic Al-Si melt under rotating magnetic field. J. Cryst. Growth 2014, 399, 43-48. [CrossRef]

20. He, Y.; Li, Q.; Liu, W. Effect of combined magnetic field on the eliminating inclusions from liquid aluminum alloy. Mater. Lett. 2011, 65, 1226-1228. [CrossRef]

21. Zou, J.; Zhai, Q.J.; Liu, F.Y.; Liu, K.M.; Lu, D.P. Influences on distribution of solute atoms in Cu-8Fe alloy solidification process under rotating magnetic field. Met. Mater. Int. 2018, 24, 1275-1284. [CrossRef]

22. Mikolajczak, P.; Ratke, L. Effect of stirring induced by rotating magnetic field on $\beta-\mathrm{Al}_{5} \mathrm{FeSi}$ intermetallic phases during directional solidification in Al-Si alloys. Int. J. Cast Met. Res. 2013, 26, 339-353. [CrossRef]

23. Lyubimova, T.P.; Ivantsov, M.A.; Khlybov, A.O.; Khlybov, O.; Zaidat, K.; Duffar, T. Influence of submerged heating on vertical Bridgman crystal growth of silicon under travelling magnetic field. J. Cryst. Growth 2019, 531, 125340. [CrossRef]

24. Ren, Z.M.; Jin, J.Z. Formation of a separated eutectic in Al-Si eutectic alloy. J. Mater. Sci. 1992, 27, 4663-4666.

25. Ban, B.Y.; Li, Y.L.; Zuo, Q.X.; Zhang, T.T.; Chen, J.; Dai, S.Y. Refining of metallurgical grade Si by solidification of Al-Si melt under electromagnetic stirring. J. Mater. Process. Technol. 2015, 222, 142-147. [CrossRef]

26. Ban, B.Y.; Zhang, T.T.; Li, J.W.; Bai, X.L.; Pan, X.; Chen, J.; Tabaian, S.H. Solidification refining of MG-Si by Al-Si alloy under rotating electromagnetic field with varying frequencies. Sep. Purif. Technol. 2018, 202, 266-274. [CrossRef]

27. Zou, Q.C.; Jie, J.C.; Sun, J.L.; Wang, T.M.; Cao, Z.Q.; Li, T.J. Effect of Si content on separation and purification of the primary Si phase from hypereutectic Al-Si alloy using rotating magnetic field. Sep. Purif. Technol. 2015, 142, 101-107. [CrossRef]

28. Zou, Q.C.; Jie, J.C.; Liu, S.C.; Sun, X.L.; Li, T.J.; Wang, T.M.; Yin, G.M. Effect of Sn addition on the separation and purification of primary Si from solidification of Al-30Si melt under electromagnetic stirring. J. Alloy. Compd. 2017, 725, 1264-1271. [CrossRef]

29. Xue, H.Y.; Lv, G.Q.; Ma, W.H.; Chen, D.T.; Yu, J. Separation mechanism of primary silicon from hypereutectic Al-Si melts under alternating electromagnetic fields. Metall. Mater. Trans. A 2015, 46, 2092-2103. [CrossRef]

30. Jiang, W.Y.; Yu, W.Z.; Li, J.; You, Z.X.; Li, C.M.; Lv, X.W. Segregation and morphological evolution of Si phase during electromagnetic directional solidification of hypereutectic Al-Si alloys. Materials 2019, 12, 10. [CrossRef]

31. Liang, S.M.; Fetzer, R.S. Phosphorus in Al-Si cast alloys: Thermodynamic prediction of the AlP and eutectic (Si) solidification sequence validated by microstructure and nucleation undercooling data. Acta Mater. 2014, 72, 41-56. [CrossRef] 
32. Zou, Q.C.; Han, N.; Zhang, Z.X.; Jie, J.C.; Xu, F.; An, X.Z. Enhancing segregation behavior of impurity by electromagnetic stirring in the solidification process of Al-30Si alloy. Metals 2020, 10, 155. [CrossRef]

33. Jie, J.C.; Liu, C.B.; Wang, S.H.; Dong, B.W.; Liu, S.C.; Li, T.J. Characterisation of steel/nickel bronze clad strips prepared by continuous solid/liquid bonding method. Mater Sci Technol. 2019, 35, 1840-1847. [CrossRef]

34. Zou, Q.C.; Jie, J.C.; Wang, T.M.; Li, T.J. An efficient method to purify metallurgical grade Si by electromagnetic semi-continuous casting of Al-30Si melt. Mater Lett. 2016, 185, 59-62. [CrossRef]

35. Won, C.W.; Nersisyan, H.H.; Won, H.I. Solar-grade silicon powder prepared by combining combustion synthesis with hydrometallurgy. Sol. Energy Mater. Sol. Cells 2019, 57, 45-750. [CrossRef]

36. Fang, M.; Lu, C.H.; Huang, L.Q.; Lai, H.X.; Chen, J.; Li, J.T.; Ma, W.H.; Xing, P.F.; Luo, X.T. Separation of metal impurities from metallurgical grade silicon via $\mathrm{CaO}-\mathrm{SiO}_{2}-\mathrm{CaF}_{2}$ slag treatment followed by leaching with hydrochloric acid. Sep. Purif. Technol. 2014, 49, 2261-2270.

37. Ding, Z.; Ma, W.H.; Wei, K.X.; Wu, J.J.; Zhou, Y.; Xie, K.Q. Boron removal from metallurgical-grade silicon using lithium containing slag. J. Non-Cryst. Solids 2012, 358, 2708-2712. [CrossRef]

38. Zhang, L.; Tan, Y.; Li, J.Y.; Liu, Y.; Wang, D.K. Study of boron removal from molten silicon by slag refining under atmosphere. Mat. Sci. Semicond. Proc. 2013, 16, 1645-1649. [CrossRef]

39. Yuge, N.; Abe, M.; Hanazawa, K.; Baba, H.; Naomichi, N.; Yoshiei, K.; Yutaku, S.; Hiwasa, S.; Aratani, F. Purification of metallurgical-grade silicon up to solar grade. Prog. Photovolt. 2001, 9, 203-209. [CrossRef]

40. Shi, S.; Dong, W.; Peng, X.; Jiang, D.C.; Tan, Y. Evaporation and removal mechanism of phosphorus from the surface of silicon melt during electron beam melting. Appl. Surf. Sci. 2013, 266, 344-349. [CrossRef]

41. Martorano, M.A.; Ferreira Neto, J.B.; Oliveira, T.S.; Tsubaki, T.O. Refining of metallurgical silicon by directional solidification. Mater. Sci. Eng. B 2011, 176, 217-226. [CrossRef]

(C) 2020 by the authors. Licensee MDPI, Basel, Switzerland. This article is an open access article distributed under the terms and conditions of the Creative Commons Attribution (CC BY) license (http://creativecommons.org/licenses/by/4.0/). 